\title{
High-Resolution Modeling of the Cape Canaveral Area Land-Water Circulations and Associated Features
}

\author{
P. Anil RaO* and Henry E. Fuelberg \\ Department of Meteorology, The Florida State University, Tallahassee, Florida \\ KeLvin K. DRoegemeieR \\ Center for Analysis and Prediction of Storms and School of Meteorology, University of Oklahoma, \\ Norman, Oklahoma
}

(Manuscript received 23 March 1998, in final form 8 September 1998)

\begin{abstract}
The Advanced Regional Prediction System is used to perform a three-dimensional numerical simulation of land-water circulations near Cape Canaveral, Florida. Three two-way nested grids having spacings of 1.6, 0.4, and $0.1 \mathrm{~km}$ are employed. Results show that the structures of both the sea and river breezes compare well with observation and theory.

Horizontal convective rolls (HCRs), Kelvin-Helmholtz instability (KHI), and their interactions with the sea and river breezes also are investigated. HCRs form over the heated land surface at periodic intervals. The HCRs have two preferred spatial scales: large and small. Inclusion of both the large and small HCRs yields aspect ratios that are smaller than most previous observations. However, when considering only the larger HCRs, agreement is better. The smaller HCRs eventually dissipate or merge with their larger HCR counterparts. These mergers intensify the vertical motion within the larger circulations.

The HCRs are observed to tilt upward in advance of the Indian River breeze (IRB), and then advect over and behind the land-water circulation. There is evidence that an HCR advects $2.5 \mathrm{~km}$ behind the surface front. The orientation of the IRB causes its interaction with an HCR to change from an intersection to a merger. This produces positive vertical vorticity that causes the IRB to rotate counterclockwise. The detailed physiography and surface characteristics used in this research allow these complex asymmetric interactions to be simulated.

In addition, the configuration of this simulation allows an even smaller-scale feature, KHI, to be observed on top of and behind the Indian River breeze front. It appears as vortices or billows that grow in amplitude and propagate backward relative to the front. The structure of the billows agrees well with previous theoretical and modeling results. Local regions of upward motion associated with the billows may be a preferred area for postfrontal convection.
\end{abstract}

\section{Introduction}

The sea breeze occurs almost daily in many coastal areas during the warm season. Thermal gradients caused by temperature differences between land and sea create onshore flow during the day (sea breeze) and offshore flow at night (land breeze). Simpson (1994) provides a detailed description of the physics and characteristics of this circulation.

\footnotetext{
* Current affiliation: Universities Space Research Association, NASA/Goddard Space Flight Center, Greenbelt, Maryland.

Corresponding author address: Dr. P. Anil Rao, Universities Space Research Association, NASA/Goddard Space Flight Center, Mesoscale Atmospheric Processes Branch, Code 912, Greenbelt, MD 20771.

E-mail: rao@gilbert.gsfc.nasa.gov
}

The sea breeze associated with the Florida peninsula has been studied extensively, both observationally and with numerical models (e.g., Pielke 1974; Burpee and Lahiff 1984). The central portion of the Florida east coast consists of a complex land-sea interface (Fig. 1). Land features include Merritt Island, Cape Canaveral, and mainland Florida, while water bodies include the Atlantic Ocean, the Indian and Banana Rivers, and Mosquito Lagoon. Because of this complex physiography, and the presence of the Kennedy Space Center (KSC), complex circulations occur over the area. In this paper we focus on the details of the land-water circulations and other features commonly found along the eastern coast of Florida.

Radar, mesonetwork, and aircraft data have been used in several observational studies to investigate the structure of the Cape Canaveral sea breeze and other circulations in the area (e.g., Atkins and Wakimoto 1997). Horizontal convective rolls (HCRs) are one of the cir- 


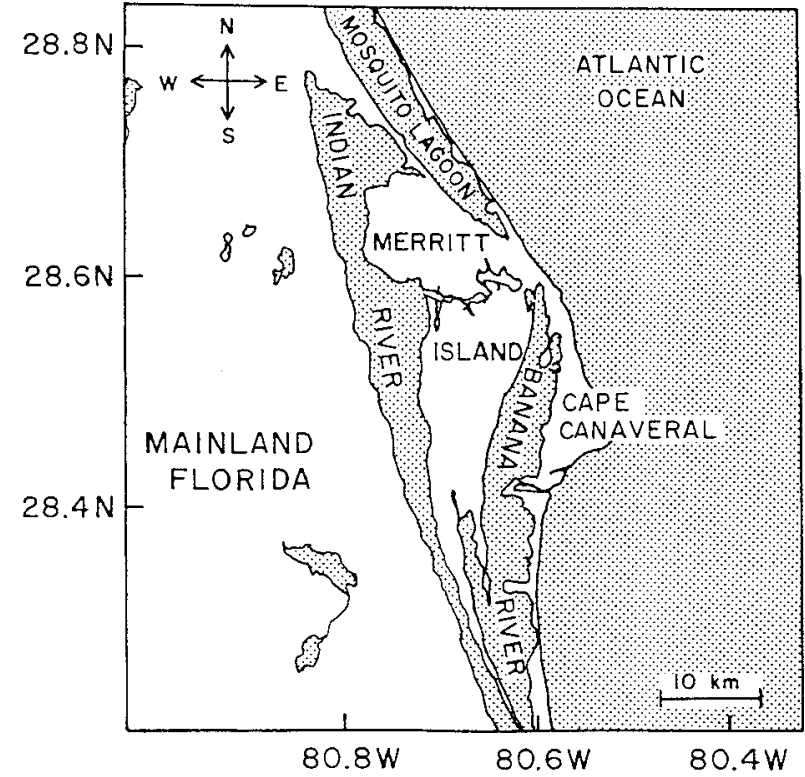

FIG. 1. Physiography near Cape Canaveral, FL.

culations frequently studied. HCRs commonly form over the heated land surface of the Florida peninsula during the summer months. They are counterrotating pairs of helices oriented horizontally within the convective boundary layer (CBL) that tend to be aligned parallel to the mean flow (Asai and Nakasuji 1973; Miura 1986). Furthermore, the ascending (descending) branches of HCRs carry moist air upward (downward) (Weckwerth et al. 1996).

Intersections between HCRs and the sea breeze front are preferred areas of convection due to the combination of like sign vertical motion. For example, Wakimoto and Atkins (1994) and Atkins et al. (1995) studied two sea breeze events during the Convection and Precipitation/Electrification project (one with offshore prevailing flow and the other with onshore prevailing flow). During the offshore flow case, HCRs were aligned nearly perpendicular to the sea breeze front. These intersections created an "alongfrontal variability" at the leading edge of the front, producing greater radar reflectivities than in those frontal areas where HCR updrafts were not present. In addition, the HCRs were found to tilt over the front, with positive reflectivities still occurring behind the front (see Fig. 6 from Atkins et al. 1995). During the onshore flow case, HCRs developed approximately parallel to the advancing sea breeze front. This caused a merger (rather than an intersection) of the HCRs and front, and it was here that cloud development occurred.

The Cape Canaveral area also has been studied using numerical models. Zhong et al. (1991) used a hydrostatic three-dimensional (3D) boundary layer model with $3-\mathrm{km}$ horizontal resolution to examine interactions between sea and river breezes. Their model successfully simulated the onset time and inland movement of the sea breeze and river breeze convergence zones. They noted that the flow field was significantly modified by the Indian and Banana Rivers. Limitations to their work included using the same water temperatures for both the rivers and ocean and the relatively coarse resolution employed. Zhong and Takle (1993) used the same model, but at $1.5-\mathrm{km}$ resolution, to investigate effects of the large-scale flow on sea and river breezes. Their results confirmed findings of earlier observational studies, for example, onshore flow creates weaker sea breeze circulations than does offshore flow (e.g., Blanchard and Lopez 1985).

Simulations with higher resolution than described above have been used to investigate density currents (e.g., sea and river breezes and thunderstorm outflow boundaries). For example, Droegemeier and Wilhelmson (1987) used a uniform resolution of $100 \mathrm{~m}$ to simulate thunderstorm outflows in two dimensions. Their model captured the explicit turbulent structure of the outflows, showing the turbulence as billows or vortex rolls resulting from Kelvin-Helmholtz instability (KHI). In particular, the Kelvin-Helmholtz billows (KHBs) were seen to form at the head of the outflow and propagate backward relative to it. Their findings agreed well with laboratory experiments (e.g., Simpson 1969). Similarly, a sea breeze circulation was simulated by Sha et al. (1991) using a horizontal resolution of $100 \mathrm{~m}$. They also noted the presence of KHBs on top of and behind the sea breeze head. They attributed the observed slowing of sea breeze propagation during the day to mixing produced by the billows. Both of these studies were limited by $2 \mathrm{D}$ planar-symmetric geometry and the use of idealized initial states.

Dailey and Fovell (1999) employed a 3D mesoscale model with horizontal resolutions as high as $500 \mathrm{~m}$ to simulate interactions between the sea breeze and HCRs. Although using an idealized initial state, they successfully simulated distinct structures of both the sea breeze and HCRs, as well as the observed "alongfrontal variability" at intersections between the HCRs and sea breeze.

Moeng and Sullivan (1994) used high-resolution large eddy simulations to investigate both shear- and buoyancy-driven boundary layer flows. They found smallscale "linear streaks" in simulations dominated by either buoyancy or shear. These features were of a smaller scale than typically observed HCRs. However, when a combination of buoyancy and shear were used, classic HCRs appeared in the simulations. The small domain size used in their simulations proved to be a limitation.

Buckley and Kurzeja (1997) performed a 3D numerical study using three grids with two-way interactive nesting to simulate the nocturnal sea breeze (land breeze) near South Carolina. Their grid resolutions were $10.0,2.5$, and $0.657 \mathrm{~km}$, employing full 3D data for initialization. Comparisons with observations indicated that the model captured general features of the nocturnal sea breeze. Although KHBs were present on top of and 
behind the sea breeze front, their structure was not consistent with those produced in laboratory experiments (e.g., Simpson and Britter 1979). Additional simulations at higher resolutions $(\sim 200 \mathrm{~m})$ produced KHBs having characteristics closer to those of theory, but still not as realistic as simulations with resolutions near $100 \mathrm{~m}$ (e.g., Sha et al. 1991). The use of uniform soil type and soil moisture for initialization was a potential limitation of their work.

To build upon this body of knowledge, we present results from a high-resolution $3 \mathrm{D}$ numerical simulation of land-water circulations over the Cape Canaveral area. The goal is not to forecast a specific event; rather, our major objective is to investigate the complex interactions that occur between the land-water circulations and other circulations (e.g., HCRs, KHBs).

Our procedures attempt to improve upon the limitations of the research just discussed, and our use of complex physiography and surface characteristics, along with the higher-resolution numerical modeling, is found to produce more realistic simulations than reported previously. In addition, we show that circulation features having differing scales (i.e., land-water circulations, HCRs, and KHBs) can be simulated concurrently using a full-physics 3D model.

Section 2 contains a brief model description plus details of our model configuration and its initialization. Section 3 presents results of the simulation, while section 4 contains a summary and conclusions.

\section{Model description and initialization}

The numerical model used for this study is the Advanced Regional Prediction System (ARPS) developed by the Center for Analysis and Prediction of Storms (CAPS) at the University of Oklahoma. Because a detailed description of the ARPS and its capabilities can be found in Xue et al. (1995), only a brief summary is given here.

The ARPS is a general purpose, nonhydrostatic, compressible model designed for storm and mesoscale simulation and prediction. The model can be configured to run in either $1 \mathrm{D}, 2 \mathrm{D}$, or $3 \mathrm{D}$ mode, and several options exist for turbulence closure, vertical grid stretching, cloud microphysics, surface physics, and radiation. Both one-way and two-way interactive nesting are available. Furthermore, the ARPS grid options are very flexible, with no limit on the refinement ratio, size of dimensions, or level of nesting. The ARPS grid scheme is based on the adaptive grid refinement strategy of Skamarock and Klemp (1993).

The simulation presented here employs three two-way nested grids (Fig. 2). The outer, middle, and inner grids consist of, respectively, $60 \times 60$ grid points at $1.6-\mathrm{km}$ resolution (D1), $81 \times 49$ grid points at $400-\mathrm{m}$ resolution (D2), and $129 \times 65$ grid points at $100-\mathrm{m}$ resolution (D3). Grid D1 includes all of Merritt Island, Cape Canaveral, and the Indian and Banana Rivers, and extends

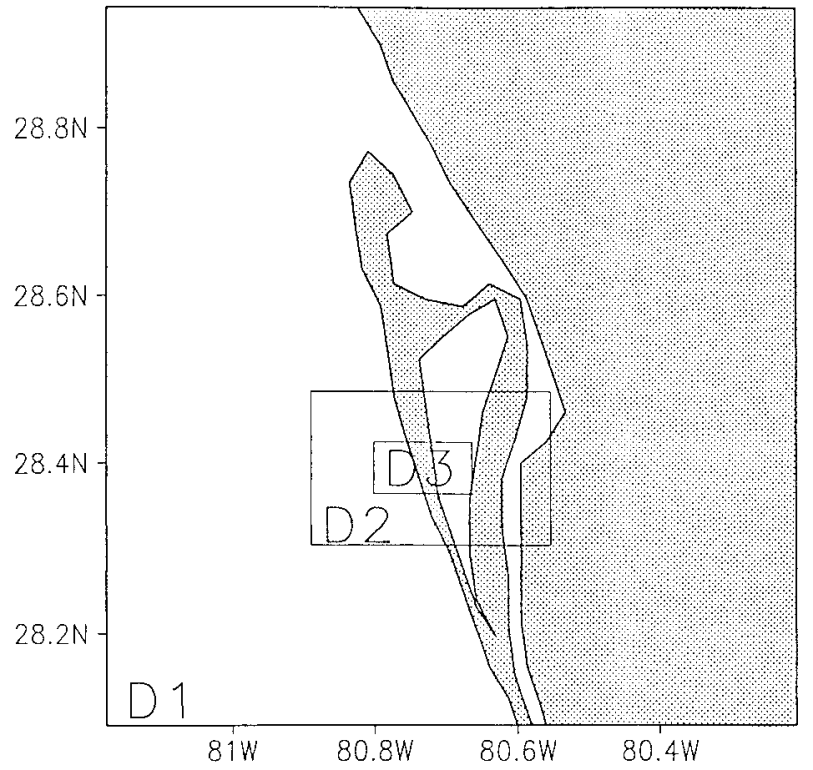

FIG. 2. Locations of the three grid domains utilized for numerical simulation. Grids D1, D2, and D3 contain horizontal resolutions of $1.6,0.4$, and $0.1 \mathrm{~km}$, respectively.

well into mainland Florida and the Atlantic Ocean. Grid D2 contains parts of Cape Canaveral, Merritt Island, and the mainland, as well as a small portion of the Atlantic Ocean. Finally, grid D3 contains parts of southern Merritt Island and mainland Florida along with a portion of the Indian River. All three grids contain 35 vertical levels. Within the lowest $750 \mathrm{~m}$, the vertical grid spacing is $35 \mathrm{~m}$, while above $750 \mathrm{~m}$ the grid is stretched with an average spacing of $300 \mathrm{~m}$. This places the model top at $\sim 10 \mathrm{~km}$. These small horizontal and vertical grid spacings are required to resolve features such as KHI (Droegemeier and Wilhelmson 1987; Sha et al. 1991; Buckley and Kurzeja 1997).

The ARPS model can be initialized using either a single sounding or a 3D horizontally inhomogenous initial state. Radar, mesonetwork, and upper air data can be assimilated using the ARPS Data Analysis System (ADAS; Brewster et al. 1994). The current simulation was initialized from data on 27 June 1996. The 1000 UTC Cape Canaveral radiosonde sounding (Fig. 3) shows that winds generally were westerly, with speeds near $4 \mathrm{~m} \mathrm{~s}^{-1}$ in the lower levels. The surface temperature was $\sim 24^{\circ} \mathrm{C}$, with a nocturnal inversion above. This day was chosen because the ambient westerly winds induced thunderstorm development at several locations along the sea and river breeze fronts.

The 1200 UTC 27 June analysis from the National Centers for Environmental Prediction mesoscale Eta Model (Black 1994) was interpolated down to the outermost ARPS grid and then blended with the 1000 UTC Cape Canaveral sounding (Fig. 3) using ADAS. Inclusion of the sounding enabled the initial conditions to contain a more realistic vertical structure near the Cape 


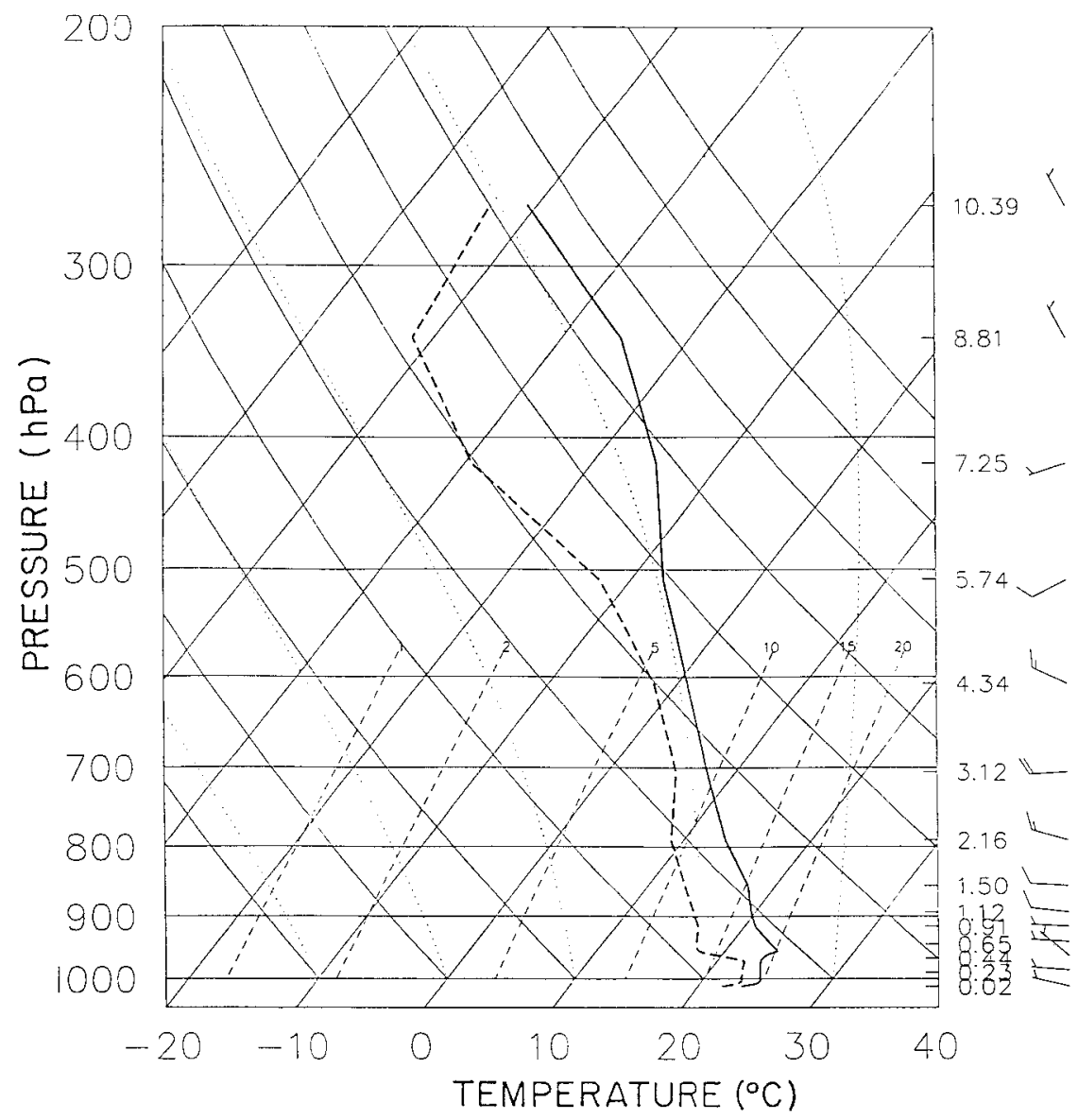

FIG. 3. Cape Canaveral sounding at 1000 UTC 27 Jun 1996 used in conjunction with the Meso-Eta analysis for model initialization. Wind in $\mathrm{m} \mathrm{s}^{-1}$ (half barb $=5 \mathrm{~m} \mathrm{~s}^{-1}$ ).

Canaveral area. The finer-resolution grids (i.e., D2 and D3) were initialized by interpolation from their parent grid (i.e., D2 was initialized from D1, and D3 was initialized from D2). The model then was run in a twoway nested mode for $7 \mathrm{~h}$. Although we are not attempting to forecast events that occurred on this day, we implement full 3D initialization to obtain the most realistic solution possible.

Soil type classification was taken from the 1-km resolution State Soil Geographic Database (PSU 1998). Both vegetation type and normalized difference vegetation index (NDVI) were derived using monthly averaged data from the Advanced Very High Resolution Radiometer on board the NOAA-11 polar orbiting satellite (Gutman 1991). USGS (1998) provides a detailed description of this dataset.

Variable soil moisture was implemented for initialization. This was achieved using a constant percentage of the difference between the saturation and wilting points of each soil type (Jacquemin and Noilhan 1990). The value $80 \%$ produced soil moisture values commonly found in the area of interest during the summer months (e.g., $\sim 35 \%$ in sandy regions and $\sim 45 \%$ in the wetter swamps). Surface skin temperature was initialized as the lowest-level air temperature $(\sim 18 \mathrm{~m})$. Inland water temperatures for the Banana and Indian Rivers and all lakes were set at $299 \mathrm{~K}$, while the ocean temperature was set at $297 \mathrm{~K}$. Open (i.e., wave radiating) lateral boundaries were used for the outermost grid, while a rigid top and bottom boundary was employed. Table 1 contains other important model settings used in the simulation.

\section{Results}

\section{a. Sea breeze}

Figure 4 shows results from the coarsest grid mesh (D1, 1.6-km resolution). The three panels contain winds at $18 \mathrm{~m}$ (Fig. 4a) and $4.39 \mathrm{~km}$ (Fig. 4b) above the surface at the initial model time, and also at $18 \mathrm{~m}$, but $4 \mathrm{~h}, 16$ min into the simulation (Figs. 4c). Hereafter, time into the simulation will be denoted as hh:mm, for example, 4:16 signifies $4 \mathrm{~h}, 16 \mathrm{~min}$ into the simulation. At the initial model time, winds near the surface (Fig. 4a) generally are from the northwest in the northern half of the 
TABLE 1. Model parameter settings for domains D1, D2, and D3.

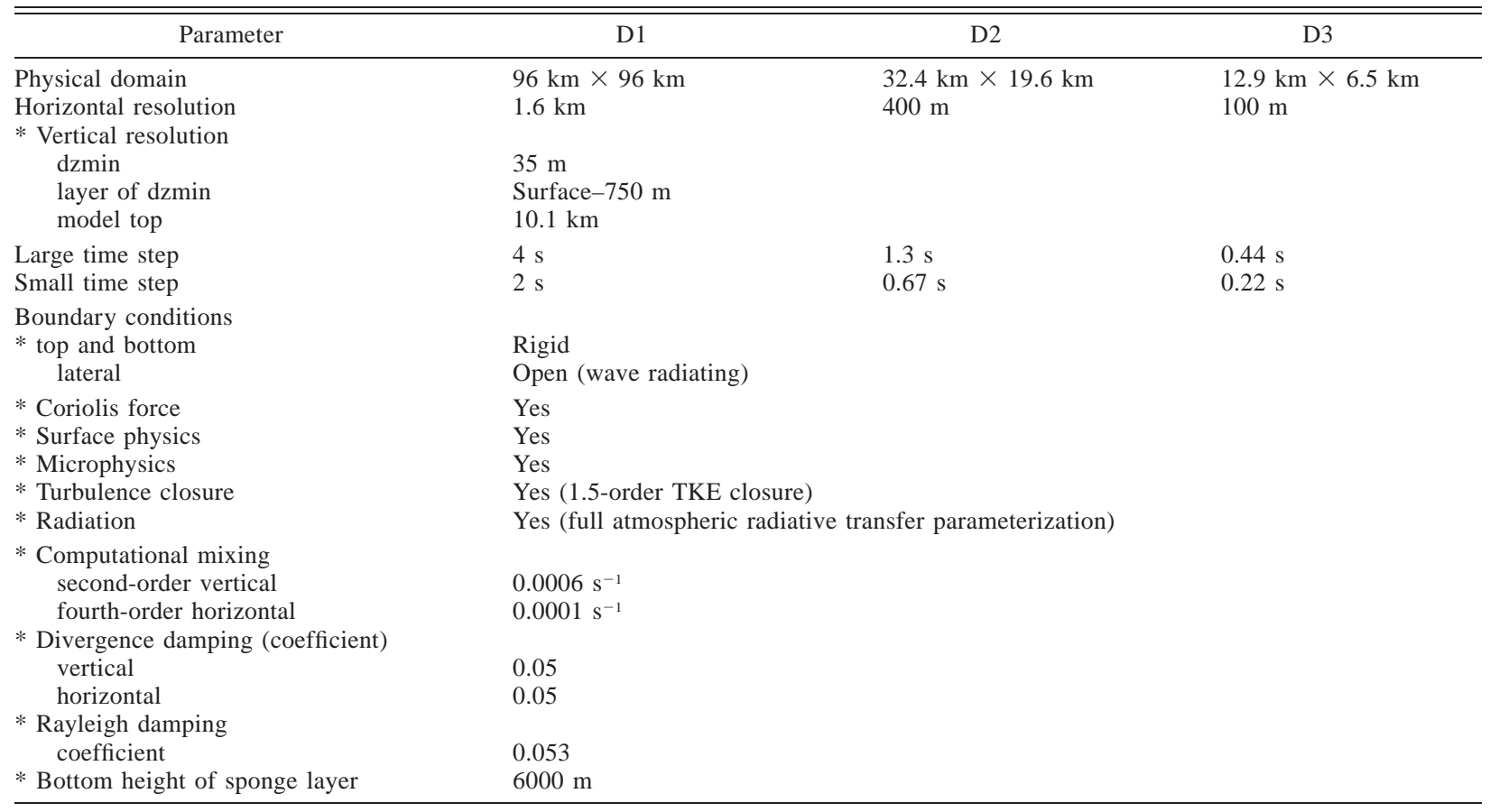

* Values are the same for all three grids.

domain but more westerly in the southern half. Middletropospheric winds (Fig. 4b) are similar to those near the surface. This flow pattern has been shown to be conducive to convective development along the Florida east coast sea breeze (Blanchard and Lopez 1985).

At 4:16, winds at $4.39 \mathrm{~km}$ (not shown) have changed, but directions at $18 \mathrm{~m}$ show a major shift (Fig. 4c). Specifically, winds over the ocean have turned onshore to produce the sea breeze, which is farther inland over the northern portion of the domain than over the southern part. For example, the sea breeze is near $80.85^{\circ} \mathrm{W}$ near latitude $28.7^{\circ} \mathrm{N}$, but barely onshore in the southern portion of the domain. This difference occurs because the ambient flow to the south has a more westerly component. Complex wind patterns over Merritt Island and the two rivers correspond to river breeze circulations. For example, divergence associated with the Indian River is seen near the center of the domain. This river breeze, combined with the westward moving sea breeze, produces an area of enhanced convergence over Merritt Island. Locations of current circulations agree well with those of previous observational (e.g., Blanchard and Lopez 1985) and modeling (e.g., Zhong et al. 1991) studies for an offshore flow regime.

Figure 5 shows an east-west cross section through D1 (axis is X1 in Fig. 4c). The solid (dashed) line is the zero $u$-wind isotach at 4:16 (4:36). This isotach is used to determine the position and depth of the sea breeze. Specifically, winds at altitudes below the zero isotach have an easterly (onshore) component, while those at higher altitudes have a westerly (offshore) com- ponent. The pattern at 4:16 indicates a developing sea breeze. The head of the sea breeze is $\sim 250 \mathrm{~m}$ deep, while the flow behind extends to a height of $\sim 180 \mathrm{~m}$. These depths are consistent with density current theory; that is, the flow behind a density current is approximately $1 / 2$ the depth of the head (Simpson and Britter 1979).

At 4:36 (dashed line), the sea breeze has become nearly stationary on the inland (western) side but extends farther into the ocean. The depth of the head (flow behind) has increased to nearly $400 \mathrm{~m}$ (200 m). These results agree with Atkins and Wakimoto (1997), who found sea breeze depths to be $\sim 400 \mathrm{~m}$ in the Cape Canaveral region during a case of offshore ambient flow. Opposing flow near the western edge of the sea breeze (not shown) causes the nearly stationary front and influences the growth of the circulation.

\section{b. Indian River breeze and HCRs}

The sea breeze front never moves through subdomain D3 during the 7-h simulation; its advance is limited by strong ambient westerly flow. However, the Indian River breeze (IRB) and well-developed HCRs do form over the area, and they can be studied in detail.

Figure 6a shows a horizontal analysis of upward vertical motion (wind field) at $52 \mathrm{~m}(18 \mathrm{~m})$ above the surface within subdomain D3 at 2:52. The IRB is identified as the line of upward motion extending northwest to southeast along the western edge of the Indian River. Maximum ascent in this region is $\sim 1 \mathrm{~m} \mathrm{~s}^{-1}$. The flow 

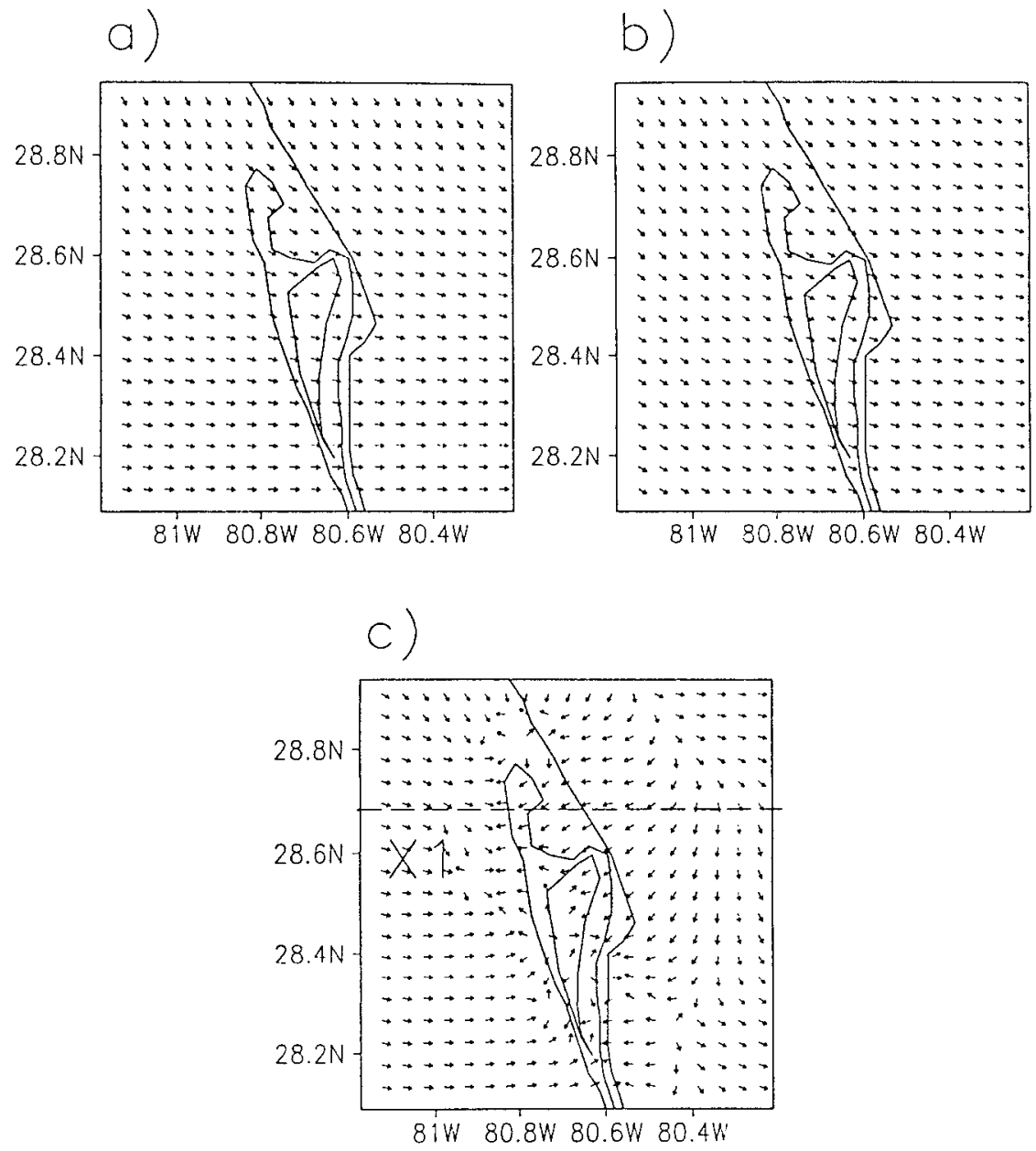

FIG. 4. Winds at (a) $18 \mathrm{~m}$ and (b) $4.39 \mathrm{~km}$ above the surface within D1 at time 0:00. (c) Winds at $18 \mathrm{~m}$ above the surface within D1 at time 4:16. Label X1 in (c) denotes the axis of the cross section shown in Fig. 5.

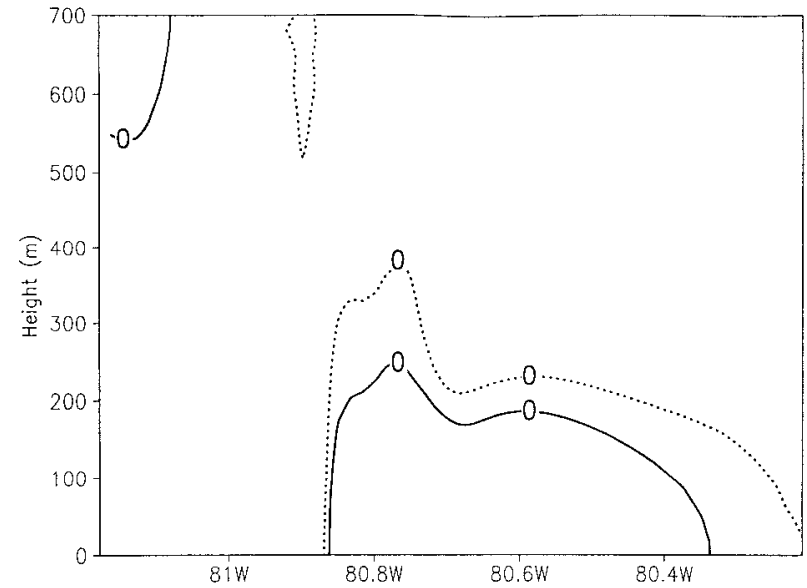

FIG. 5. Cross section of the zero $u$-wind isotach $\left(\mathrm{m} \mathrm{s}^{-1}\right)$ along $\mathrm{X} 1$ at time 4:16 (solid) and 4:36 (dashed). Axis of the cross section is shown in Fig. 4c. in advance of (i.e., to the west of ) the IRB generally is from the west. The flow behind the front exhibits several interesting features.

Specifically, winds over the river generally have northerly and easterly components. This northerly component is due to the shape of the Indian River north of D3 (Fig. 2) and the slight northerly component in the initial flow over this area (Fig. 4a). As the river widens near $28.55^{\circ} \mathrm{N}, 80.75^{\circ} \mathrm{W}$ (Fig. 2), divergence off the southern edge of this wider portion enhances the northerly wind component already present south of the area (i.e., within D2 and D3). The small discontinuous pockets of upward motion east of the Indian River are evidence of an eastward moving IRB. The IRB on the eastern side is weaker than on the western side because both the ambient flow and IRB have westerly components on the eastern side of the river, and because surface temperatures over Merritt Island are cooler as compared to mainland Florida $\left(1-2^{\circ}\right.$, not shown). The cooler surface temperatures and ambient westerly winds also prohibit the development of a westward moving Banana 

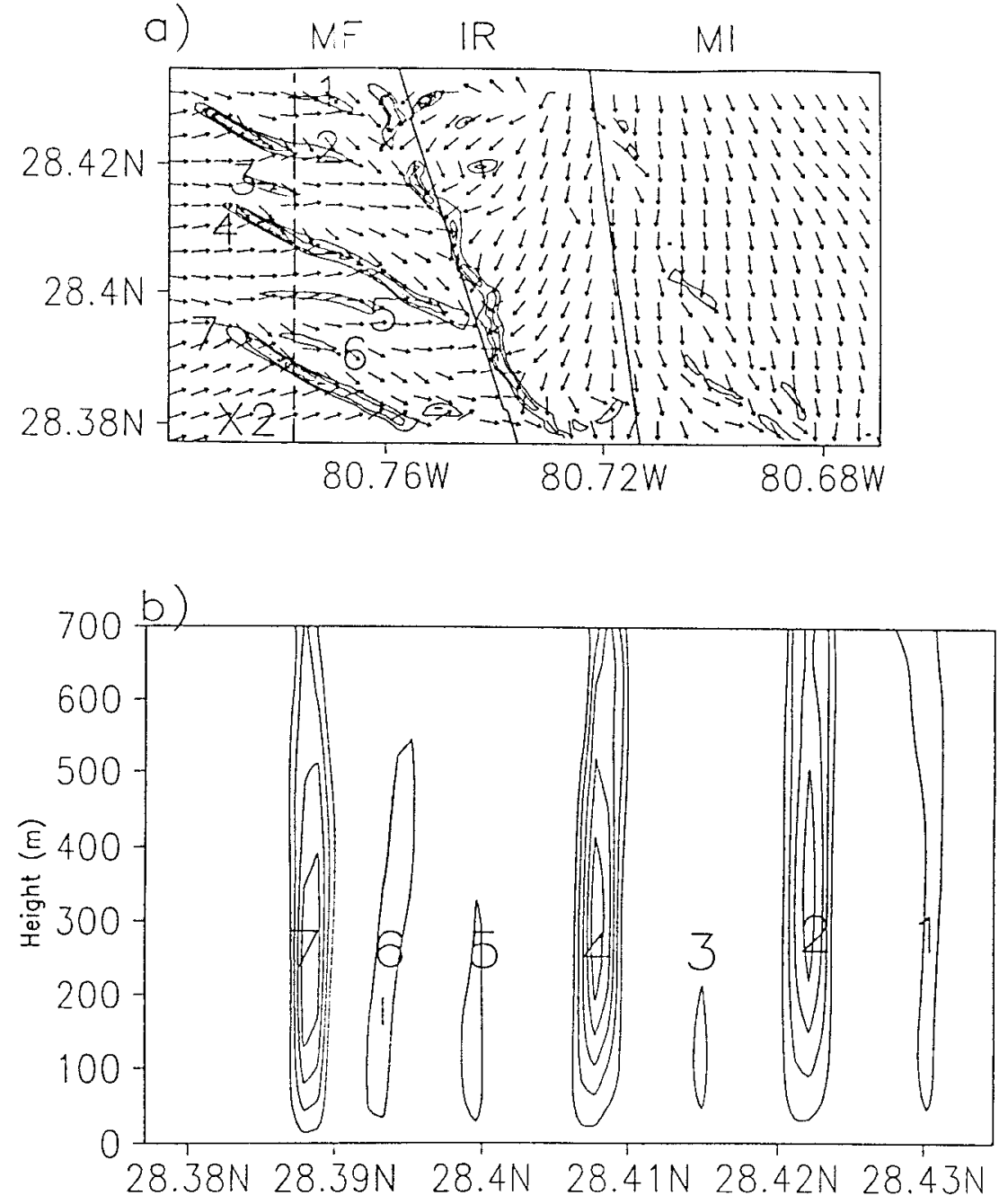

FIG. 6. (a) Vertical motion $\left(\mathrm{m} \mathrm{s}^{-1}\right)$ at $52 \mathrm{~m}$ above the surface and wind field at $18 \mathrm{~m}$ within D3 at time 2:52. Labels MF, IR, and MI indicate location of mainland Florida, Indian River, and Merritt Island, respectively. (b) North-south cross section of upward vertical motion (m $\mathrm{s}^{-1}$ ) along X2 at time 2:52. Contour interval is $1.0 \mathrm{~m} \mathrm{~s}^{-1}$. Values range from 0.5 to $4.5 \mathrm{~m} \mathrm{~s}^{-1}$. Location of the cross section is designated $\mathrm{X} 2$ in the top panel. Numbers in both panels denote locations of HCRs $1-7$.

River breeze, that is, the lack of easterly winds on the easternmost portion of the domain bordering the Banana River.

West of the IRB (Fig. 6a), seven elongated lines of upward motion are oriented northwest to southeast (labeled 1-7). They are spaced $\sim 750 \mathrm{~m}$ apart and are aligned along the mean boundary layer wind, with maximum upward motions of $\sim 1.5 \mathrm{~m} \mathrm{~s}^{-1}$ at $52 \mathrm{~m}$ above the ground. Circulations 2, 4, and 7 have greater lengths and stronger upward motion than do circulations 1,3 , 5 , and 6 . Figure $6 \mathrm{~b}$ shows a cross section of upward vertical motion along an axis nearly perpendicular to these circulations (denoted X2 on Fig. 6a). Numbers 1-7 denote the circulations shown in Fig. 6a. Circulations 2,4 , and 7 extend through the top of the boundary layer ( $\sim 700 \mathrm{~m}$ based on profiles of virtual potential temperature). Their vertical motions are much larger than those of the remaining circulations, which generally are more shallow.

Although the seven circulations in Fig. 6a have two distinct spatial scales (i.e., circulations 2,4 , and 7 vs 1 , 3,5 , and 6 ), their proximity to one another (i.e., they are adjacent), along with their orientation, suggest that both sets are a type of HCR. To investigate this issue further, aspect ratios (i.e., the ratio of the cross-roll wavelength to the boundary layer depth) were computed. When using the average spacing between all seven circulations $(\sim 750 \mathrm{~m})$, the aspect ratio is $\sim 1.07$. Although this value is smaller than those from most previous observational (e.g., Atkinson and Zhang 1996) 

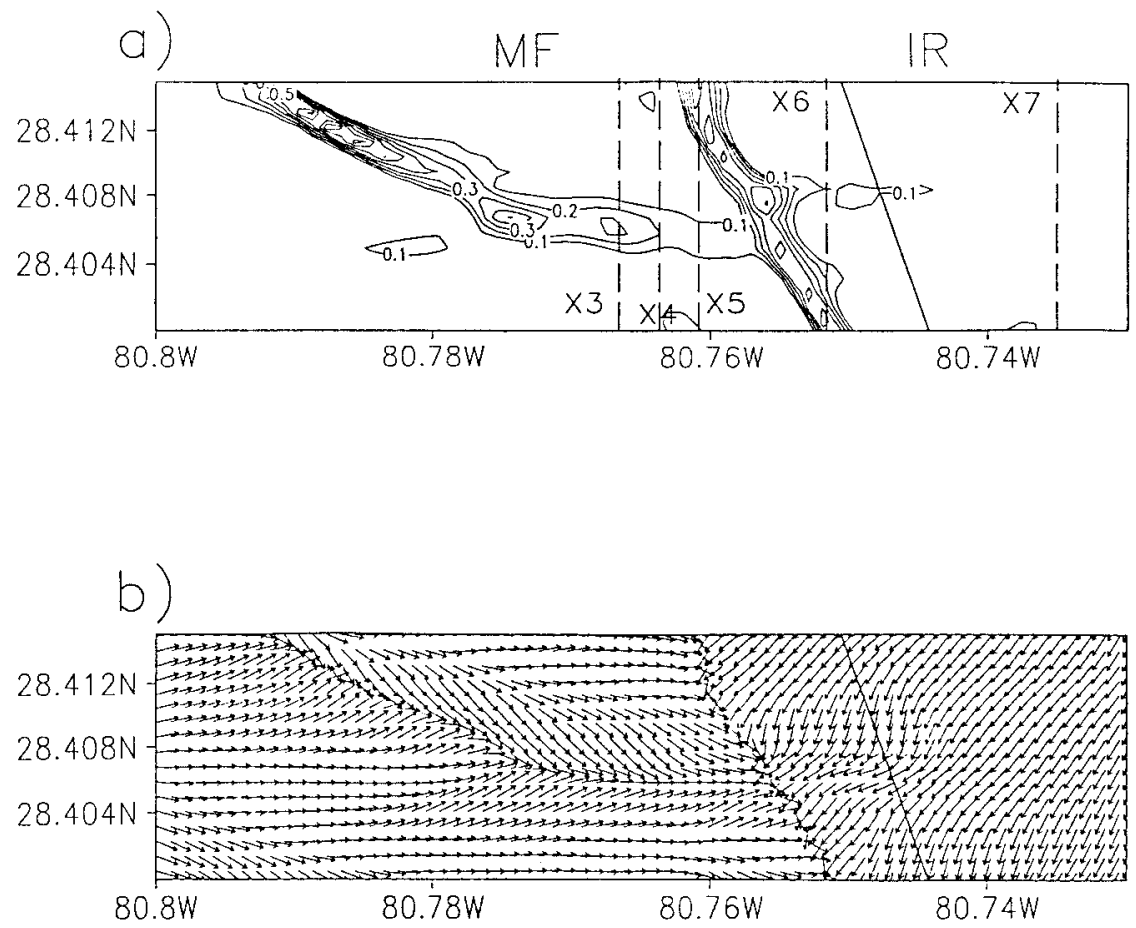

FIG. 7. (a) Upward vertical motion $\left(\mathrm{m} \mathrm{s}^{-1}\right)$ at $52 \mathrm{~m}$ above the surface and (b) wind field 18 $\mathrm{m}$ above the surface, within a portion of D3 at time 3:08. Values in (a) range from 0.1 to $0.6 \mathrm{~m}$ $\mathrm{s}^{-1}$ with a contour interval of $0.1 \mathrm{~m} \mathrm{~s}^{-1}$. Labels X3-X7 denote cross sections shown in Figs. 8 and 9. Here, MF and IR are as in Fig. 6.

and modeling (e.g., Dailey and Fovell 1999) studies, Weckwerth et al. (1997b) recently observed similar small scale HCRs using high-resolution lidar data.

Since HCRs typically reach peak intensity during the afternoon, we first suspected that small sensible heat flux at this time might lead to the small aspect ratios in our simulation. (It was not possible to determine the structure of the HCRs during the time of strongest heating since outflow boundaries produced by convection near 3:30 effectively destroyed the HCRs.) In their modeling study, Weckwerth et al. (1997a) found smaller HCR aspect ratios within those environments having relatively small sensible heat flux. For example, they found aspect ratios of 1.45 (1.6) associated with sensible heat fluxes of 25 (200) $\mathrm{W} \mathrm{m}^{-2}$. Because sensible heat flux in our region ranges from 170 to $180 \mathrm{~W} \mathrm{~m}^{-2}$ at this time, this factor may not be the major cause for the simulated spatial scales.

We believe our relatively small aspect ratios can be explained by noting that most previous values were determined from satellite imagery, that is, using cloud streets to determine HCR spacing. In our simulation, cloud water is present only in HCRs 2, 4, and 7 (not shown). Thus, if the simulation could be viewed from a satellite, the intermediate circulations would not be visible. If only HCRs 2, 4, and 7 are used to compute the aspect ratio, the value $(\sim 2.85)$ is consistent with previous studies. The evolution of the HCRs between
2:52 and the appearance of outflow boundaries (i.e., $\sim 3$ : 30) will be discussed in section $3 \mathrm{~d}$.

\section{c. HCR interaction with the IRB}

With further heating during the simulation period, the IRB propagates slightly westward and interacts with the HCRs over the peninsula. The depth of the IRB at this time ranges from 50 to $200 \mathrm{~m}$. Figure 7 shows upward vertical motion at $52 \mathrm{~m}$ above the surface (Fig. 7a) and the horizontal wind field at $18 \mathrm{~m}$ (Fig. 7b) in a portion of D3 at time 3:08. The IRB is the elongated region of low-level convergence and ascending motion stretching from northwest to southeast, while the region extending northwest from the IRB is HCR 4 (see Fig. 6a). Maximum vertical motion is $0.7 \mathrm{~m} \mathrm{~s}^{-1}$ near the surface along HCR 4, decreasing from west to east.

We investigated whether HCR 4 is tilted upward in advance of the westward moving IRB. Cross sections of vertical motion spaced $300 \mathrm{~m}$ apart were prepared at three locations west of the IRB (Fig. 8, axes denoted $\mathrm{X} 3-\mathrm{X} 5$ in Fig 7a). Along X3 and X4, HCR 4 is seen clearly as a maximum in upward motion between two regions of subsidence (Figs. 8a,b). HCR 4 still is present along X5 (Fig. 8c), but an additional maximum of upward motion is seen to the north. This ascent is associated with the IRB, which has intersected the cross section at this location (the $u$-wind zero isotach is plotted 


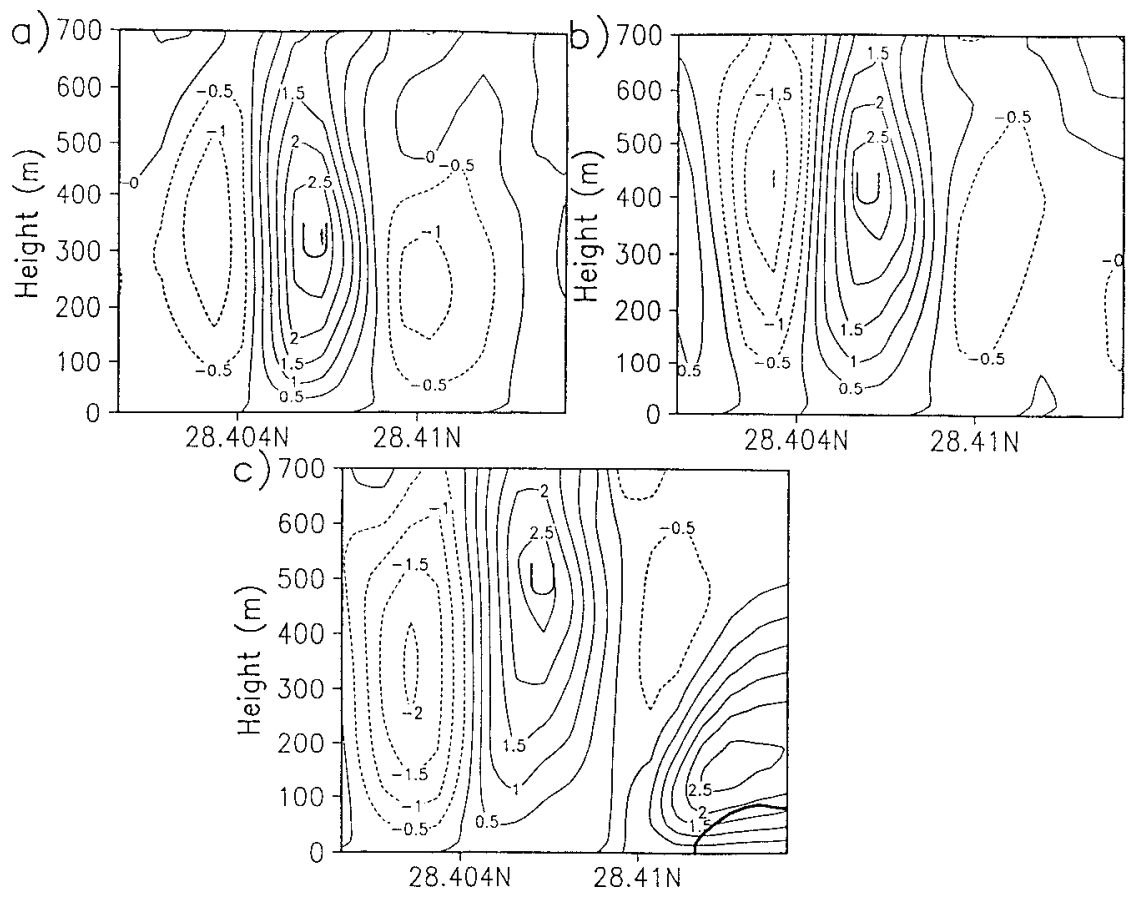

FIG. 8. Cross sections of vertical motion along axes (a) X3, (b) X4, and (c) X5 in Fig. 7a at time 3:08. The zero $u$-wind isotach is shown in (c) as a thick solid line. Solid (dashed) lines designate ascent (descent). Contour interval is $0.5 \mathrm{~m} \mathrm{~s}^{-1}$. The altitude of maximum upward motion is denoted by "U." Locations of cross sections are indicated in Fig. 7a.

for reference). Evidence that the IRB is tilting HCR 4 as the IRB moves westward is found in the altitudes of maximum upward motion within HCR 4 (labeled "U") along the different cross sections. Specifically, these altitudes are $\sim 310, \sim 410$, and $\sim 500 \mathrm{~m}$ on $\mathrm{X} 3, \mathrm{X} 4$, and $\mathrm{X} 5$, respectively. The slope of this tilt is $\sim 18^{\circ}$, which agrees well with previous observational studies (Atkins et al. 1995).

A relative maximum in upward motion can be seen (Fig. 7a) near the intersection between HCR 4 and the IRB. This maximum is caused by the combining of like sign vertical motions associated with the two circulations. It is similar to the "alongfrontal variability" discussed in Atkins et al. (1995). Behind (east of) the IRB, an undulation in the contour pattern and relative maximum in vertical motion extend east of the IRB-HCR 4 intersection. This maximum ascent, along with the surface convergence behind the front (Fig. 7b), suggest that HCR 4 is advecting behind the IRB. Specifically, as the IRB moves westward, it tilts the HCR up and over the frontal surface. This situation has been noted in previous studies of sea breeze-HCR interactions (Atkins et al. 1995; Dailey and Fovell 1999).

To verify this advective process, horizontal vorticity (along the $x$ axis) was computed behind the IRB. Figure $9 \mathrm{a}$ is a north-south cross section of horizontal vorticity just behind the intersection between HCR 4 and the IRB (X6 on Fig. 7a). The zero $u$-wind isotach also is plotted. A maximum in horizontal vorticity is located at the southernmost (left) edge of the plot near the zero $u$-wind isotach (top of the IRB). This maximum is associated with the IRB surface front; that is, strong horizontal gradients in vertical motion associated with the front create large values of horizontal vorticity. In addition, maxima in negative and positive horizontal vorticity are evident near the zero $u$-wind isotach straddling latitude $28.41^{\circ} \mathrm{N}$. These maxima are associated with HCR 4. Specifically, the negative (positive) values of horizontal vorticity indicate cyclonic (anticyclonic) rotation about the $x$ axis. Maximum ascent associated with HCR 4 is located between these two circulations.

Additional cross sections indicate the distance that HCR 4 extends behind the IRB. Figure $9 \mathrm{~b}$ shows the easternmost cross section (denoted X7 in Fig. 7a) in which there is evidence of HCR 4. The negative maximum along the zero $u$-wind isotach near the southernmost edge of the cross section is associated with HCR 7, which has advected over the IRB farther to the south (not shown). Farther north, near $29.42^{\circ} \mathrm{N}$, the negativepositive couplet near the zero $u$-wind isotach associated with HCR 4 still is present (although much weaker than in Fig. 9a). One should note that the vorticity couplet has shifted slightly northward (e.g., the negative maximum located at the center of Fig 9a now is located at $28.41^{\circ} \mathrm{N}$, while the positive maximum is just north of the cross section). Furthermore, the vorticity couplet in $\mathrm{X} 7$ is at a higher altitude than in $\mathrm{X} 6$, consistent with the depth of the IRB at these locations. Cross section 

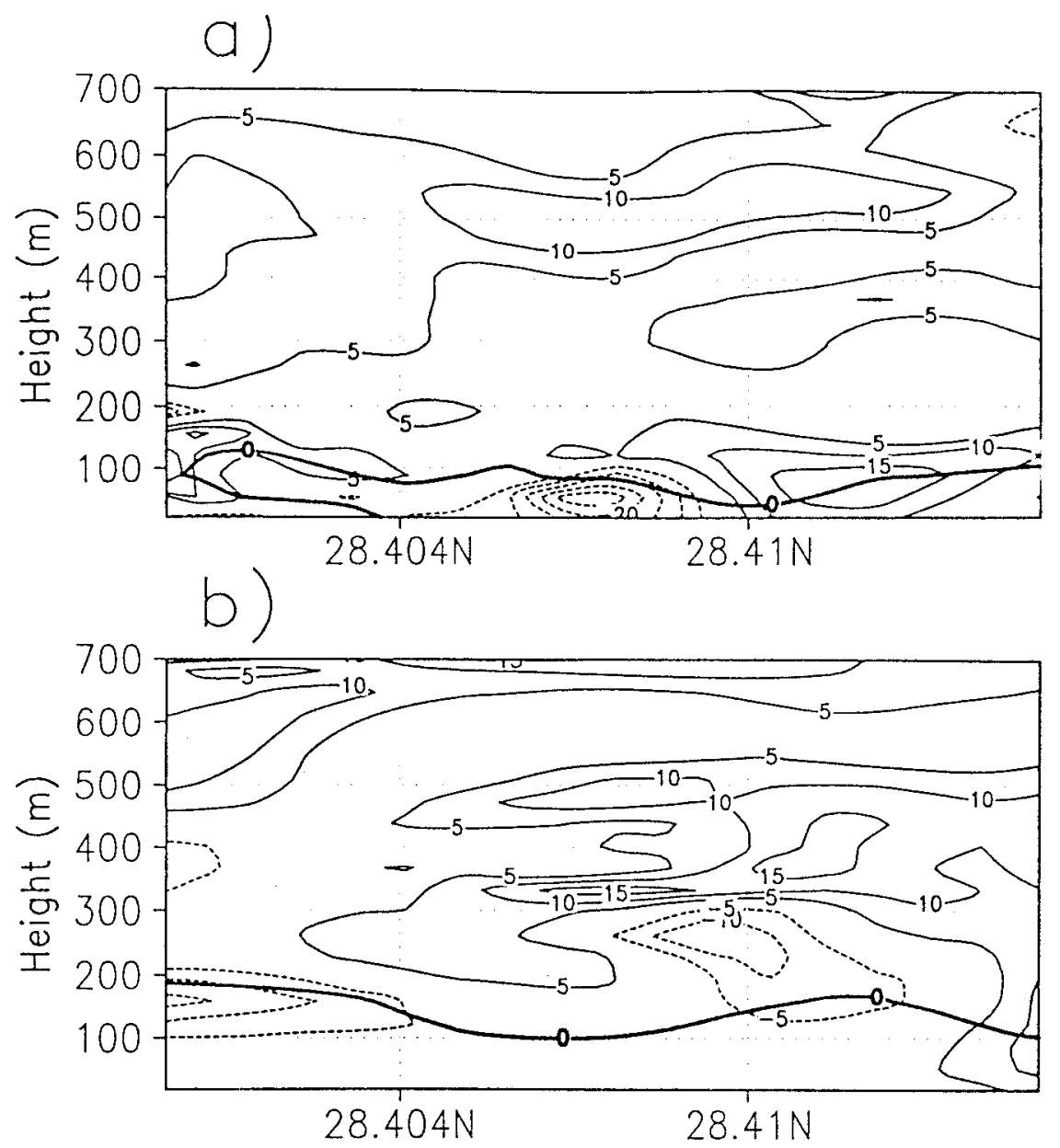

FIG. 9. Cross section of horizontal vorticity $\left(\times 10^{-3} \mathrm{~s}^{-1}\right)$ along axes (a) X6 and (b) X7 denoted in Fig. 7a at time 3:08. Solid (dashed) lines denote positive (negative) vorticity. Contour interval is $5 \times 10^{-3} \mathrm{~s}^{-1}$. The zero vorticity contour is not shown. Thick solid line is the zero $u$-wind isotach.

X7 is approximately $2.5 \mathrm{~km}$ behind the HCR 4-IRB intersection. Previous studies have shown HCRs advecting $2 \mathrm{~km}$ behind the sea breeze front (Atkins et al. 1995; Dailey and Fovell 1999).

At 3:12 (i.e., 4 min after the time just discussed), HCR 4 has started to affect the structure of the IRB. Figure 10a shows the wind field, while Fig. 10b contains vertical vorticity and the zero $u$-wind isotach, at $52 \mathrm{~m}$ above the ground. The wind field indicates that the IRB has moved slightly westward in the northern half of the domain (compare to Fig. 7b) but has remained nearly stationary in the southern half. In fact, the IRB exhibits a slight "bowing" or change in curvature, due to the orientation of the IRB as it interacts with the HCR (i.e., the IRB and HCR 4 are not strictly perpendicular). Thus, as the IRB propagates westward with a northwestsoutheast orientation, its interaction with HCR 4 changes from an intersection (Fig. 7) to a merger (Fig. 10). The wind flow associated with each convergence line produces positive vertical vorticity along the merger
(Fig. 10b). This scenario causes the IRB to rotate in the cyclonic fashion seen in Fig. 10. These types of interactions between HCRs and land-water circulations have not been previously simulated due to the idealized conditions (e.g., straight coastlines, uniform wind shear, etc.) used in earlier modeling studies (e.g., Dailey and Fovell 1999; Weckwerth et al. 1997a).

\section{d. HCR mergers/decay}

Figure 11 shows cross sections of upward vertical motion along X2 (Fig. 6a) at times 3:00 (Fig. 11a), 3: 08 (Fig. 11b), and 3:16 (Fig. 11c). The numbers identify the HCRs discussed in Fig. 6. One should note the appearance of another circulation (labeled 8 in Fig. 11a), which was not present 8 min earlier in D3 (Fig. 6b). At 3:16 (Fig. 11c), only HCRs 2, 4, and 7 are present. Data at intermediate times show that the smaller HCRs have merged with the larger circulations. Specifically, HCRs 5 and 6 move south and merge with HCR 7 (Fig. 6b 

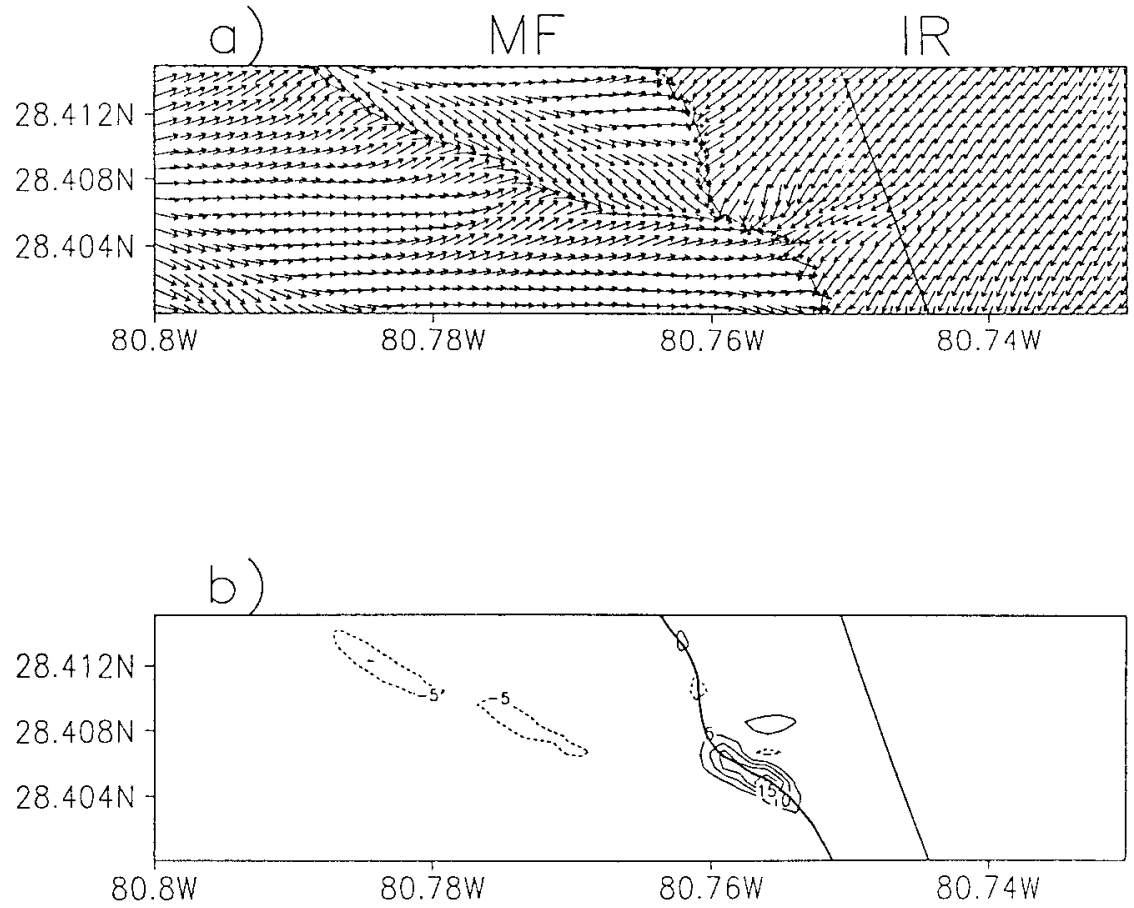

FIG. 10. (a) Wind field and (b) vertical vorticity $\left(\times 10^{-3} \mathrm{~s}^{-1}\right) 52 \mathrm{~m}$ above the surface within a portion of D3 at time 3:12. Solid (dashed) lines denote positive (negative) vorticity. The zero vorticity vector is not shown. Also shown is the zero $u$-wind isotach.
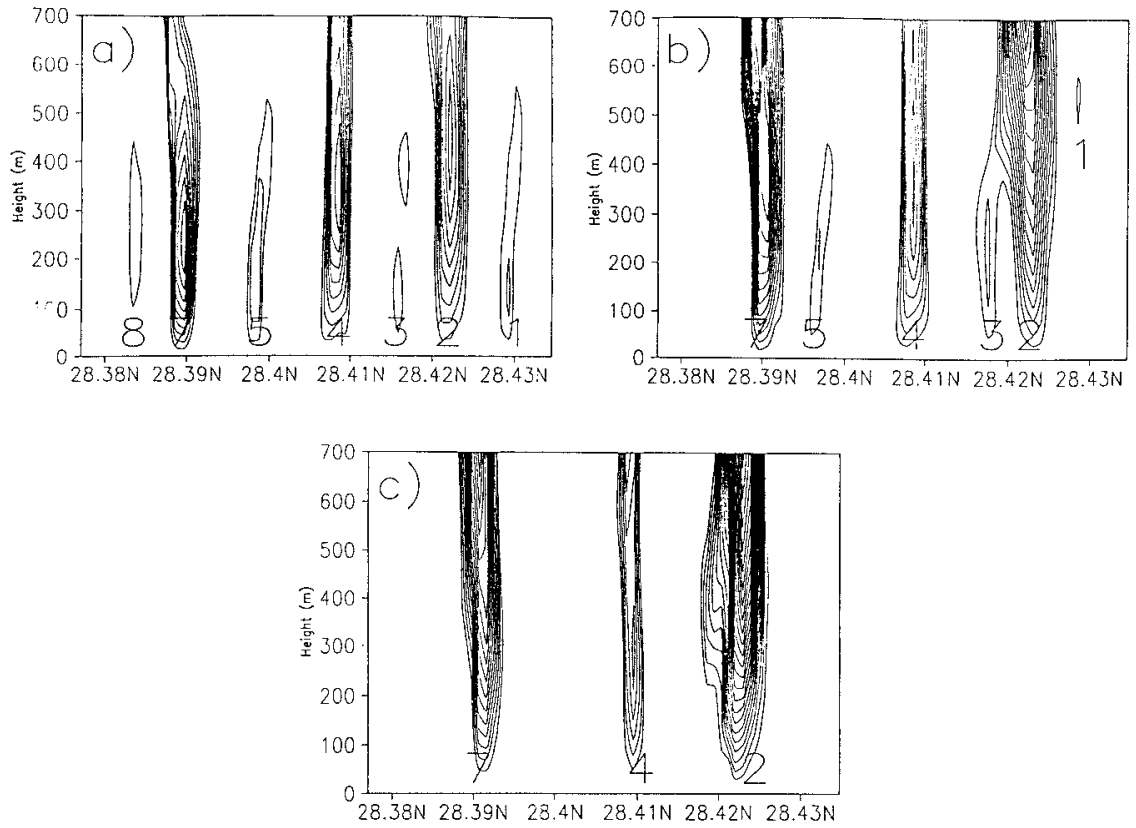

FIG. 11. Upward vertical motion along X2 (axis denoted in Fig. 6a) at times (a) 3:00, (b) 3: 08 , and (c) 3:16. Contour interval is $0.5 \mathrm{~m} \mathrm{~s}^{-1}$. Contours are from 0.5 to $14 \mathrm{~m} \mathrm{~s}^{-1}$. Numbers correspond to HCRs shown in Fig. 6. 


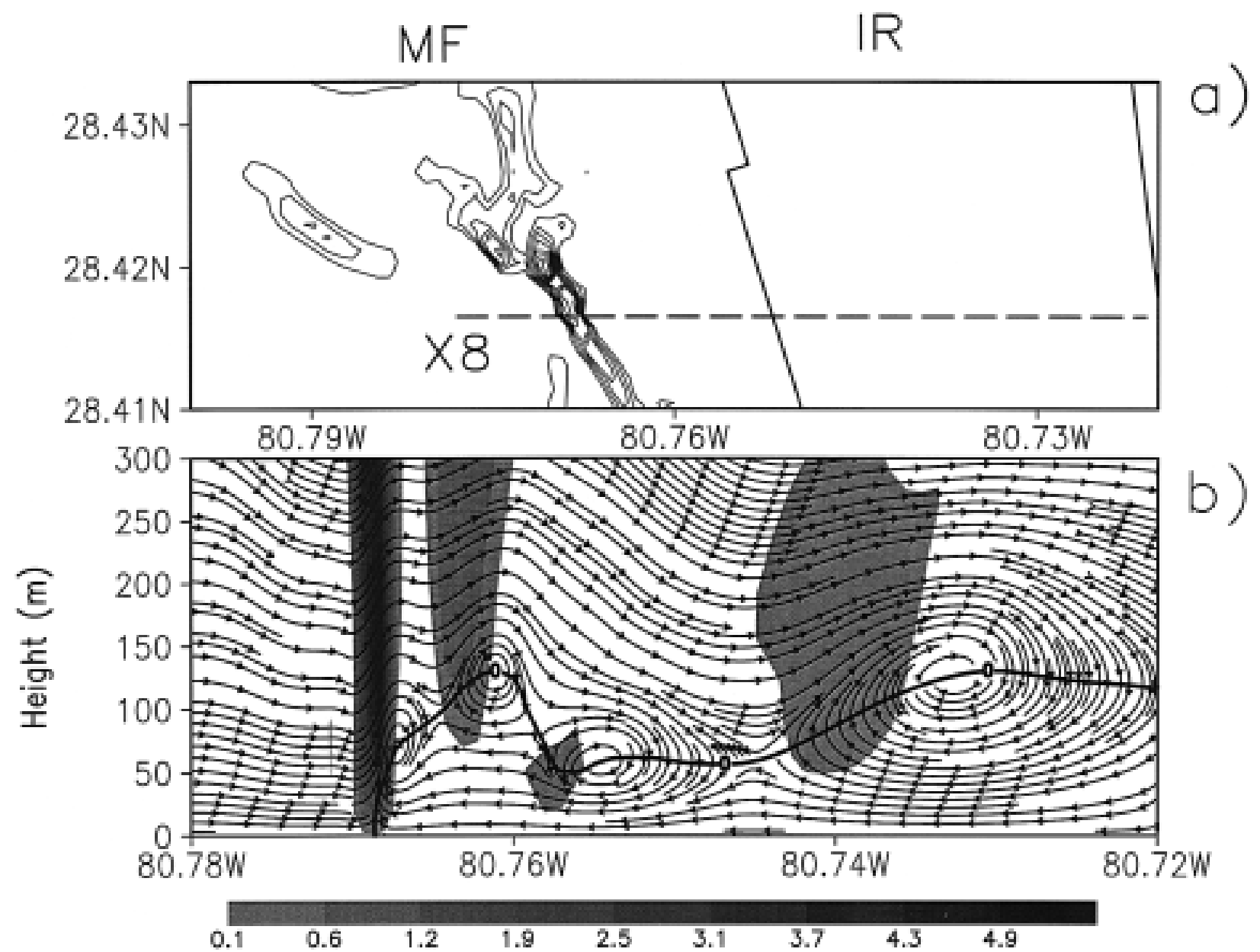

FIG. 12. (a) Upward vertical motion $\left(\mathrm{m} \mathrm{s}^{-1}\right) 52 \mathrm{~m}$ above the surface within a portion of $\mathrm{D} 3$ at time $3: 28$. Values range from 0.5 to $5 \mathrm{~m}$ $\mathrm{s}^{-1}$. Contour interval is $0.5 \mathrm{~m}^{-1}$. (b) Cross section of $u-w$ wind flow along axis $\mathrm{X} 8$ denoted in top panel. Also shown is the zero $u$-wind isotach (thick solid line) and upward vertical motion (shaded, $\mathrm{m} \mathrm{s}^{-1}$ ).

and Fig. 11a for HCR 6; Figs. 11a-c for HCR 5). Similarly, HCR 1 moves south and combines with HCR 2 (Figs. 11a,b), while HCR 3 moves north and combines with HCR 2 (Figs. $11 \mathrm{a}-\mathrm{c}$ ). Finally, HCR 8 moves north and merges with HCR 7 (Figs. 11a,b). Animations of these cross sections clearly show the progression of the smaller HCRs toward the larger circulations.

Vertical motion in HCR 7 increases as it consolidates with the smaller-scale circulations (i.e., $\sim 4 \mathrm{~m} \mathrm{~s}^{-1}, \sim 6$ $\mathrm{m} \mathrm{s}^{-1}$, and $\sim 8 \mathrm{~m} \mathrm{~s}^{-1}$ at 3:00, 3:08, and 3:16, respectively; Fig. 11). Atkins et al. (1995) discussed the merger of an HCR with a sea breeze front and also found increases in vertical motion. HCR 2 also exhibits an increase in vertical motion; however, a developing thunderstorm at its intersection with the IRB makes it difficult to differentiate the source of that increase.

It is interesting to note that HCR 4 weakens during the times shown in Fig. 11 (i.e., from $\sim 4 \mathrm{~m} \mathrm{~s}^{-1}$ to $\sim 2.5$ $\mathrm{m} \mathrm{s}^{-1}$ ). This can be explained as follows: The downdrafts on each side of HCR 4 initially produce surface flow that converges in the center and sustains the HCR
4 updraft. Thus, when the adjacent downdrafts weaken (i.e., when HCR 3 and 5 propagate north and south, respectively), the associated surface outflow also weakens, thereby diminishing the updraft in the middle (i.e., HCR 4). Aspect ratios during this period steadily increase as the smaller-scale HCRs either decay (i.e., HCR 4) or merge with the larger circulations (i.e., HCRs 1, $3,5,6$, and 8 ), yielding values in closer agreement with previous observations.

\section{e. $K H I$}

Figure 12a shows a horizontal analysis of vertical motion $52 \mathrm{~m}$ above the ground over a portion of D3 at $3: 28$. The IRB still has not moved appreciably westward due to the relatively strong ambient westerly winds. A complex pattern of surface vertical motion is present near $28.425^{\circ} \mathrm{N}$ where a thunderstorm has developed at the intersection point between the IRB surface front and HCR 2. Farther south, strong vertical directional shear is associated with the easterly (westerly) winds behind 
(in front of) the IRB. The occurrence of KHI in this scenario of large shear (e.g., atop density currents) has been discussed in previous observational (e.g., Hardy et al. 1973), laboratory (e.g., Simpson and Britter 1979), and modeling (e.g., Droegemeier and Wilhelmson 1987) studies.

To determine whether KHI is present in the current case, a cross section of $u-w$ streamlines was constructed perpendicular to the IRB along the strong shear zone (Fig. 12b, denoted X8 in Fig. 11a). The zero $u$-wind isotach and upward vertical motion also are plotted. The striking feature is four vorticies centered over the zero $u$-wind isotach (the top of the IRB). These appear to be KHBs in different stages of their lifetimes. Specifically, KHBs initiate at the head of a density current and then grow in amplitude as they propagate backward relative to the front (Simpson 1969).

To determine whether these vortices were produced from KHI, Richardson numbers were computed along the zero $u$-wind isotach. Previous studies have shown that the Richardson number must be less than 0.25 for KHI to initiate (e.g., Miles and Howard 1964). However, $\mathrm{KHI}$ can remain as long as the Richardson number is less than 1.0 (Wallace and Hobbs 1977). Richardson numbers along the zero $u$-wind isotach in Fig. 12b range from $\sim 0.15$ near the head (i.e., where they develop) to $\sim 0.40$ on the eastern portion of the domain. Thus, current values are consistent with the theoretical ranges.

Wavelengths of KHBs have varied from $0.5 \mathrm{~km}$ (Sha et al. 1991) to $20 \mathrm{~km}$ (Buckley and Kurzeja 1997). Current wavelengths range from $\sim 600 \mathrm{~m}$ near the head to $2.5 \mathrm{~km}$ near the easternmost portion of the figure. To further quantify the presence of KHBs, we computed the ratio between the maximum amplitude and horizontal wavelength of the billows. Past research has shown a wide range of ratios, that is, from 0.01 (e.g., Buckley and Kurzeja 1997) to 1.0 (e.g., Britter and Simpson 1978). Our mean value of $\sim 0.1$ falls within this range. The above parameters support the hypothesis that the simulated vortices result from KHI atop the IRB. In addition, animations of the current cross section clearly reveal the KHBs originating at the head of the river breeze, growing in amplitude, and then propagating backward relative to the front.

The pattern of vertical motion (Fig. 12b) shows distinct pockets of ascent along each KHB. Values reach $\sim 0.4 \mathrm{~m} \mathrm{~s}^{-1}$ along the easternmost billow (near $80.74^{\circ} \mathrm{W}$ ), which is located over $2 \mathrm{~km}$ behind the surface front. These areas might be preferable for postfrontal convection if adequate forcing is supplied in the stable air below. This scenario is under investigation in another simulation and will be presented in a future paper.

\section{Summary and conclusions}

We have presented results from a high-resolution, 3D simulation over the Cape Canaveral area. The structures of land-water circulations and other features (HCRs,
KHI) were investigated. Complex interactions between HCRs and the IRB also were described. The ARPS model was initialized with an inhomogenous initial state and run in a two-way interactive mode. Three nested grids with spacings of $1.6,0.4$, and $0.1 \mathrm{~km}$ were used. The research documents the ability to simultaneously simulate several circulations of differing scales.

Results indicated that the structure and dimensions of the sea breeze agreed well with those of previous studies. HCRs were seen to form over the heated land surface ahead of the Indian River breeze. The HCRs had two distinct structures. When all HCRs were considered, aspect ratios were smaller than most previous observations. However, when only the larger rolls were considered, aspect ratios were consistent with past research.

An HCR was found to tilt upward in advance of the IRB, and then advect over and behind that density current. The HCR appeared to be present $2.5 \mathrm{~km}$ behind the IRB front. The orientation of the IRB caused its interaction with an HCR to change from an intersection to a merger. As a result, the IRB rotated in a counterclockwise fashion at the merger. These asymmetric interactions were possible due to the complex physiography and surface characteristics used in this research. Eventually, the smaller HCRs either merged with the larger circulations or decayed. The mergers with the larger circulations caused an increase in vertical motion within the larger HCRs.

An even smaller-scale phenomena, KHI, was seen atop the IRB in the form of billows. Future research will investigate whether the upward motion associated with these features can aid convective initiation behind the frontal boundary.

Small-scale circulation features (i.e., HCRs and KHI) were not resolved on the $1.6-\mathrm{km}$ grid. Instead, they required grid spacings less than $1 \mathrm{~km}$, and in the case of KHI, less than a few hundred meters. Previous research has indicated that interactions among these features define preferred areas of convection. This suggests that for mesoscale modeling to be useful for real-time forecasting in the Cape Canaveral area, nested grids with horizontal spacings less than $1 \mathrm{~km}$ will be necessary. Although this is not currently possible due to the present state of computing, it might be achieved in the near future.

Acknowledgments. We would like to thank Dr. John Manobianco of the Applied Meteorology Unit at the KSC and Mr. Yuhe Liu of CAPS for answering many questions regarding the simulations. Mr. Bill Roeder and the entire staff of the U.S. Air Force 45th Weather Squadron have provided valuable insight into local meteorological issues. This research was supported by $\mathrm{Su}-$ baward S96-75662 from the Cooperative Program for Operational Meteorology, Education, and Training under a cooperative agreement between the Air Force Weather Agency (AFWA) and the University Corporation for Atmospheric Research (UCAR). The simu- 
lations were performed on the Environmental Computing Applications System Cray J90 at the University of Oklahoma. This facility is supported by the University of Oklahoma and by the National Science Foundation under Grant EAR95-12145 to the third author. The third author was supported by the National Science Foundation under Grant ATM92-20009 to CAPS. The views expressed herein are those of the authors and do not reflect the views of AFWA or UCAR.

\section{REFERENCES}

Asai, T., and I. Nakasuji, 1973: On the stability of Ekman boundary layer flow with thermally unstable stratification. J. Meteor. Soc. Japan, 51, 29-42.

Atkins, N. T., and R. M. Wakimoto, 1997: Influence of the synopticscale flow on sea breezes observed during CaPE. Mon. Wea. Rev., 125, 2112-2130.

,-- , and T. M. Weckwerth, 1995: Observations of the seabreeze front during CaPE. Part II: Dual-Doppler and aircraft analysis. Mon. Wea. Rev., 123, 944-968.

Atkinson, B. W., and J. W. Zhang, 1996: Mesoscale shallow convection in the atmosphere. Rev. Geophys., 34, 403-431.

Black, T. L., 1994: The new NMC mesoscale Eta model: Description and forecast examples. Wea. Forecasting, 9, 265-278.

Blanchard, D. O., and R. E. Lopez, 1985: Spatial patterns of convection in south Florida. Mon. Wea. Rev., 113, 1282-1299.

Brewster, K., F. Carr, N. Lin, J. Straka, and J. Krause, 1994: A local analysis system for initializing real-time convective-scale models. Preprints, Tenth Conf. on Numerical Weather Prediction, Portland, OR, Amer. Meteor. Soc., 596-598.

Britter, R. W., and J. E. Simpson, 1978: Experiments on the dynamics of a gravity current head. J. Fluid Mech., 88, 223-240.

Buckley, R. L., and R. J. Kurzeja, 1997: An observational and numerical study of the nocturnal sea breeze. Part I: Structure and circulation. J. Appl. Meteor., 36, 1577-1598.

Burpee, R. W., and L. N. Lahiff, 1984: Area-average rainfall variations on sea-breeze days in south Florida. Mon. Wea. Rev., 112, 520-534.

Dailey, P. S., and R. G. Fovell, 1999: Numerical simulation of the interaction between the sea-breeze front and horizontal convective rolls. Part I: Offshore ambient flow. Mon. Wea. Rev., 127, 858-878.

Droegemeier, K. K., and R. B. Wilhelmson, 1987: Numerical simulation of thunderstorm outflow dynamics. Part I: Outflow sensitivity experiments and turbulence dynamics. J. Atmos. Sci., 44, 1180-1210.

Gutman, G., 1991: Vegetation indices from AVHRR: An update and future prospects. Remote Sens. Environ., 35, 121-138.

Hardy, K. R., R. J. Reed, and G. K. Mather, 1973: Observation of Kelvin-Helmholtz billows and their mesoscale environment by radar, instrumented aircraft, and a dense radiosonde network. Quart. J. Roy. Meteor. Soc., 99, 279-293.

Jacquemin, B., and J. Noilhan, 1990: Sensitivity study and validation of a land surface parameterization using the HAPEX-MOBILHY data set. Bound.-Layer Meteor., 52, 93-134.

Miles, J. W., and L. N. Howard, 1964: Note on a heterogeneous shear flow. J. Fluid Mech., 20, 331-336.

Miura, Y., 1986: Aspect ratios of longitudinal rolls and convection cells observed during cold air outbreaks. J. Atmos. Sci., 43, 2639.

Moeng, C.-H., and P. P. Sullivan, 1994: A comparison of shear- and buoyancy-driven planetary boundary layer flows. J. Atmos. Sci., 51, 999-1022.

Pielke, R. A., 1974: A three-dimensional numerical model of the sea breezes over south Florida. Mon. Wea. Rev., 102, 115-139.

PSU, cited 1998: Soil information for environmental modeling. [Available online at http://dbwww.essc.psu.edu/soil_info/ soil_data $/ 1 \mathrm{~km} / \mathrm{statsgo.html.]}$

Sha, W., T. Kawamura, and H. Ueda, 1991: A numerical study on sea/land breezes as a gravity current: Kelvin-Helmholtz billows and inland penetration of the sea-breeze front. J. Atmos. Sci., 48, 1649-1665.

Simpson, J. E., 1969: A comparison between laboratory and atmospheric density currents. Quart. J. Roy. Meteor. Soc., 95, 758765 .

_ 1994: Sea Breeze and Local Wind. Cambridge University Press, 234 pp.

— current advancing over a horizontal surface. J. Fluid Mech., 94, 477-495.

Skamarock, W., and J. B. Klemp, 1993: Adaptive grid refinement for two-dimensional and three-dimensional nonhydrostatic atmospheric flow. Mon. Wea. Rev., 121, 788-804.

USGS, cited 1998: North American land cover characteristics data base. [Available online at http://edcwww.cr.usgs.gov/landdaac/ glcc/tablambert_na.html.]

Wakimoto, R. M., and N. T. Atkins, 1994: Observations of the seabreeze front during CaPE: Part I: Single-Doppler, satellite, and cloud photogrammetry analysis. Mon. Wea. Rev., 122, 10921114.

Wallace, J. M., and P. V. Hobbs, 1977: Atmospheric Science: An Introductory Survey. Academic Press, 467 pp.

Weckwerth, T. M., J. W. Wilson, and R. M. Wakimoto, 1996: Thermodynamic variability within the convective boundary layer due to horizontal convective rolls. Mon. Wea. Rev., 124, 769-784. ,$--\longrightarrow$, and N. A. Crook, 1997a: Horizontal convective rolls: Determining the environmental conditions supporting their existence and characteristics. Mon. Wea. Rev., 125, 505-526.

- C. J. Grund, and S. D. Mayor, 1997b: Linearly-organized coherent structures in the surface layer. Preprints, 12th Symp. on Boundary Layers and Turbulence, Vancouver, BC, Canada, Amer. Meteor. Soc., 22-23.

Xue, M., K. K. Droegemeier, V. Wong, A. Shapiro, and K. Brewster, 1995: ARPS version 4.0 user's guide. $380 \mathrm{pp}$. [Available from Center for Analysis and Prediction of Storms, University of Oklahoma, Norman, OK 73019-1011.]

Zhong, S., and E. S. Takle, 1993: The effects of large-scale winds on the sea-land breeze circulations in an area of complex coastal heating. J. Appl. Meteor., 32, 1181-1195.

- J. M. Leone Jr., and E. S. Takle, 1991: Interaction of the sea breeze with a river breeze in an area of complex coastal heating. Bound.-Layer Meteor., 56, 101-139. 